\title{
Cytochrome P450 27B1 Gene Polymorphism rs10877012 and rs4646536 in Patients with Systemic Lupus Erythematosus
}

\author{
ZAN LIU, MEIQIONG HUANG ${ }^{1}$, YUNXIA ZHANG², YIXI XING¹, QIANQI LIN¹ AND WEIFEI CHEN*
}

Department of Tropical Diseases Division, ${ }^{1}$ Department of Rheumatology, The Second Affiliated Hospital of Hainan Medical University, Haikou, Hainan 570311, ²Department of Scientific Laboratory, Hainan Medical University, Haikou, Hainan 571199, China

Liu et al.: Cytochrome P450 27B1 Gene Polymorphism in Patients with Systemic Lupus Erythematosus

\begin{abstract}
Systemic lupus erythematosus is a severe inflammatory connective tissue disease induced by autoimmunity. The cytochrome p450 27B1 gene, activating Vitamin D precursor 25-hydroxyvitamin $D$ into 1,25-dihydroxyvitamin $D$ in immunity cells resulted in autoimmune disorders. This study was assessing the correlation and clinical pathological characteristics relationship between the cytochrome p450 27B1 gene polymorphism rs10877012/rs4646536 and systemic lupus erythematosus to provide a rationale for determining the role that cytochrome p450 27B1 gene polymorphism plays in systemic lupus erythematosus. In this study, we investigated the association of $\mathrm{rs10877012}$ (T/G) polymorphism with systemic lupus erythematosus susceptibility in $\mathbf{1 5 6}$ patients with systemic lupus erythematosus compared to 156 healthy population, both groups came from the same Mendelian population by conformity to Hardy Weinberg equilibrium. DNA was extracted from peripheral leukocytes and analyzed for the polymorphism using the polymerase chain reaction-ligase detection reaction method. We found an association between the presence of the $T$ allele at the polymorphic site (odds ratio=2.94; $95 \%$ confidence interval 1.77-4.86; $<0.0001$ ) and a decreased colorectal cancer incidence. rs10877012 polymorphism was associated with arthritis and positive Anti-double stranded DNA antibody and increased C-reactive protein happened in patients with systemic lupus erythematosus.
\end{abstract}

Key words: Cytochrome p450 27B1, gene polymorphism, rs10877012, rs4646536, systemic lupus erythematosus

Systemic Lupus Erythematosus (SLE) is a diffuse inflammatory connective tissue disease induced by autoimmunity. Hyperreactivity of T cells and excessive viability of B cells are important pathological features of SLE ${ }^{[1]}$, which produce many harmful auto antibodies. 1,25-Dihydroxyvitamin $\mathrm{D}\left(1,25(\mathrm{OH})_{2} \mathrm{VD}\right)$ is an active form of vitamin $\mathrm{D}$, which can inhibit the expression of pro-inflammatory cytokines and increase the antiinflammatory cytokines and regulate the activity of immune cells ${ }^{[2]}$. However, the genetic mechanism of SLE has not been fully understood. Vitamin D is an essential vitamin to human life and health. The deficiency of vitamin D can cause autoimmune diseases like SLE ${ }^{[3]}$. Cytochrome p450 2R1 (CYP2R1), Cytochrome p450 27B1 (CYP27B1), Cytochrome p450 24A1 (CYP24A1), Group-Specific Component (GC) and Vitamin D Receptor (VDR), as the key regulatory genes of vitamin $\mathrm{D}$, play important roles in vitamin D metabolism and transport, and they are closely related to many important physiological functions such as cytokine secretion and $\mathrm{B}$ cell activation ${ }^{[4]}$. CYP27B1 is the most important hydroxylase to convert vitamin $\mathrm{D}$ precursor 25-hydroxyvitamin $\mathrm{D}$ (25-OH$\mathrm{VD)}$ into $1,25(\mathrm{OH})_{2} \mathrm{VD}^{[5]}$. It was demonstrated that rs10877012 and rs4646536 polymorphism in the gene influenced the circulating vitamin $\mathrm{D}$ level ${ }^{[6]}$. In this study, the messenger RNA expression profile and gene polymorphism of CYP27B1 in SLE population was demonstrated and we also studied the relationship between gene polymorphism of CYP27B1 and SLE to elucidate the role of abnormal variation of genes related to vitamin $\mathrm{D}$ metabolic pathway in the pathogenesis

*Address for correspondence

E-mail: 13036087586@163.com 
of lupus erythematosus. We found that rs10877012 genotypes TT and GT in SLE patients were higher than those in the control group and genotype GG were lower than those in the control group.

\section{MATERIALS AND METHODS}

\section{Characteristics of sample set:}

156 outpatients and inpatients with SLE from November 2019 to November 2020 were enrolled, all of them confirmed SLE by SLE diagnostic criteria ${ }^{[7]}$, the average age of the patients was $28.66 \pm 3.42 \mathrm{y}$ and the average Systemic Lupus Erythematosus Disease Activity Index (SLEDAI) score was 15.36 $\pm 11.87 ; 156$ healthy medical staff without SLE in our hospital were enrolled as the control group, with an average age of $25.04 \pm 0.88 \mathrm{y}$. There was no significant difference in age and gender among each group $(\mathrm{p}>0.05)$. All subjects had obtained informed consent and signed the informed consent before enrollment.

\section{Measurement of gene expression of vitamin D metabolic pathway:}

$60 \mathrm{ml}$ peripheral venous bloods from SLE group and control group were extracted; the cells were treated by cell lysis and proteinase $\mathrm{K}$ digestion protein to extract total DNA by AxyPre-P Whole Blood Genomic (AXYGEN) DNA Kit. The concentration and purity of DNA were measured by ultraviolet spectrophotometry and $0.8 \%$ agarose gel electrophoresis. The $-1260 \mathrm{G} / \mathrm{T}$ (rs10877012) and $+2838 \mathrm{~T} / \mathrm{C}$ (rs4646536) genotypes of CYP27B1 in total DNA were measured by Polymerase Chain Reaction (PCR)-ligase detection reaction. The primers were designed by primer 5.0 software, which sequence was shown in Table 1 . The PCR reaction conditions are: pre-denaturation at $95^{\circ}$ for $15 \mathrm{~min}$, denaturation at $94^{\circ}$ for $30 \mathrm{~s}$, annealing/extension at $56^{\circ}$ for $1 \mathrm{~min}$ and $72^{\circ}$ for $1 \mathrm{~min} .35$ cycles are carried out on
Applied Biosystems (ABI) 7500 PCR instrument and the reaction is terminated at 72 for $7 \mathrm{~min}$.

After mixing $1 \mu \mathrm{l}$ of the PCR product with loading buffer ( $1 \mu 1$ ILS500+9 $\mu 1$ formamide), the PCR product was separated by Performance-Optimized Polymer 4 gel electrophoresis and analyzed the sequence by ABI3500 DNA sequencer. The electrophoresis temperature was $6^{\circ}$, injection time was $15 \mathrm{~s}$, injection voltage was $1.2 \mathrm{kV}$, electrophoresis voltage was $15 \mathrm{kV}$ and electrophoresis time was $1500 \mathrm{~s}$. Gene mapper $^{\circledR}$ ID-X software was used to analyze the electrophoresis results and obtain gene analysis map.

\section{Verification conformity to Hardy Weinberg equilibrium:}

The distribution of different genotypes of rs10877012 and rs4646536 in SLE patients was evaluated by direct counting method and the frequency of genotype distribution of each Single Nucleotide Polymorphisms (SNPs) locus in SLE group and control group were statistically analyzed to determine whether it conforms to Hardy Weinberg equilibrium. $\mathrm{p}>0.05$ indicates that the subjects came from the same Mendelian population.

\section{Measurement of the pathogenic risk assessment of different genotypes of rs10877012:}

The clinical characteristics and laboratory indicators of 156 SLE patients were followed up. Unconditional logistic regression model was used to calculate the Odds Ratio (OR) of rs10877012 and rs4646536 genotypes with clinicopathological features (renal damage, photosensitivity, vasculitis, artis) and laboratory indicators Antinuclear Antibody (ANA), Anti-double stranded DNA antibody (anti dsDNA) and increased C-Reactive Protein (CRP) in 156 patients with SLE, expressed by $95 \%$ Confidence Interval (CI).

TABLE 1: THE SEQUENCES OF THE PRIMERS

\begin{tabular}{lcc}
\hline Gene Name & \multicolumn{1}{c}{ Forward primer } & Reverse primer \\
\hline -1260G/T & 5'-AATGAGGGAGTAAGGAGCAG-3' & 5'-AGAGAGGGCCTGTCTCTAAA-3' \\
$+2838 T / C$ & 5'-CAGTCTAGGTTGCAAAGCAC-3' $^{\prime}$ & 5'-GTTGGAAACAATGAGAAGGG-3' $^{\prime}$ \\
GAPDH & 5'-CACCATCTTCCAGGAGCGAG-3' & 5'-TGATGACCCTTTTGGCTCCC-3' \\
\hline
\end{tabular}




\section{Statistical analysis:}

Statistical analysis was conducted by Statistical Package for the Social Sciences (SPSS) 22.0 software. The enumeration data present in the form of $\mathrm{n}(\%)$ and statistical analyzed by $\chi^{2}$ test. Paired T-test was used to compare two groups and independent sample T-test was used for the comparison between three groups. $\mathrm{p}<0.05$ demonstrated that the difference between groups was statistically significant. Test and analyze whether the distribution of each genotype conformed to Hardy Weinberg equilibrium. The measurement data conform to the normal distribution and are expressed as Mean \pm Standard Deviation ( $\mathrm{x} \pm \mathrm{SD}$ ). T-test was used for comparison between groups. Logistic regression was used to multivariate analysis with significant level of Alpha $(\alpha)=0.05$.

\section{RESULTS AND DISCUSSION}

There were three genotypes at rs10877012 locus: genotype TT, GT and GG. The number of genotype TT in the SLE group was 72 cases (46.15\%), the number of genotype GT in the SLE group was 67 cases (42.95 $\%$ ), the number of genotype GG in the SLE group was 17 cases $(10.90 \%)$. The frequency of $\mathrm{T}$ allele was 54.49 $\%$, while the frequency of G allele was $45.51 \%$; in the control group, the number of genotype TT was 56 cases $(35.90 \%)$, the number of genotype GT was 55 cases $(35.26 \%)$ and the number of genotype GG was 45 cases $(28.85 \%)$. The frequency of T allele was $41.03 \%$ and the frequency of $\mathrm{G}$ allele was $58.97 \%$. Compared with the control group, there was significant difference in the distribution of genotype and allele frequency between the two groups $(p<0.05)$. Genotypes TT and GT in SLE patients were higher than those in the control group and genotype GG were lower than those in the control group. See Table 2 for details.
There were three genotypes at rs4646536 locus: genotype CC, CT and TT. The number of genotype CC in SLE group was 78 cases (50.00\%), the number of genotype CT in SLE group 61 cases $(39.10 \%)$ and the number of genotype TT in SLE group 17 cases (10.90 $\%$ ). The frequency of $\mathrm{C}$ allele was $67.95 \%$ and the frequency of T allele was $32.05 \%$; in the control group, there were 73 cases of genotype CC (46.79\%), 56 cases of genotype CT (35.90\%) and 27 cases of genotype TT $(17.31 \%)$. The frequency of $\mathrm{C}$ allele was $62.18 \%$ and the frequency of $\mathrm{T}$ allele was $37.82 \%$. Compared with the two groups, there was no significant difference in the distribution of genotype and allele frequency between the two groups ( $p>0.05)$. See Table 3 for details.

The $\chi^{2}$ of Hardy Weinberg equilibrium test of SLE group at rs 10877012 locus was $0.844(\mathrm{p}=0.357)$, while the $\chi^{2}$ of Hardy Weinberg equilibrium test of control group was $0.006(\mathrm{p}=0.921)$. The $\chi^{2}$ of Hardy Weinberg equilibrium test of SLE group at rs4646536 locus was $1.416(\mathrm{p}=0.359)$, while the $\chi^{2}$ of Hardy Weinberg equilibrium test of control group was $1.426(\mathrm{p}=0.513)$, as shown in Table 4 and Table 5.

Through the logistic regression analysis, the different genotypes of rs10877012 locus were analyzed with the clinicopathological characteristics of SLE patients (renal damage, photosensitivity, vasculitis and arthritis). The results showed that the genotype distribution of rs10877012 locus was correlated with the occurrence of arthritis $(\mathrm{p}<0.05)$. The incidence of arthritis was higher in GT genotype carriers. However, there was no significant difference between the genotype distribution of rs10877012 and renal damage, photosensitivity and vasculitis $(\mathrm{p}>0.05)$. See Table 6 for details.

TABLE 2: THE RESULTS OF rs10877012 GENOTYPE DISTRIBUTION AND ALLELE FREQUENCY

\begin{tabular}{lcccc}
\hline & SLE group $(\mathrm{n}=156)$ & Control group $(\mathrm{n}=156)$ & $\mathrm{i}$ \\
\cline { 2 - 3 } & $\mathrm{n}(\%)$ & $\mathrm{n}(\%)$ & \\
\hline Genotype distribution & & & \\
TT & $72(46.15 \%)$ & $56(35.90 \%)$ & \\
GT & $67(42.95 \%)$ & $55(35.26 \%)$ & 15.825 & 0.0004 \\
GG & $17(10.90 \%)$ & $45(28.85 \%)$ & \\
Allele & & & \\
T & $85(54.49 \%)$ & $71(41.03 \%)$ & \\
G & $64(45.51 \%)$ & $92(58.97 \%)$ & 5.665 & 0.0174 \\
\hline
\end{tabular}


TABLE 3: THE RESULTS OF rs4646536 GENOTYPE DISTRIBUTION AND ALLELE FREQUENCY

\begin{tabular}{|c|c|c|c|c|}
\hline & $\begin{array}{c}\text { SLE group }(n=156) \\
n(\%)\end{array}$ & $\begin{array}{c}\text { Control group }(n=156) \\
n(\%)\end{array}$ & $x^{2}$ & $\mathrm{P}$ \\
\hline Genotype distribution & & & \multirow{4}{*}{2.652} & \multirow{4}{*}{0.2655} \\
\hline CC & 78 (50.00 \%) & 73 (46.79\%) & & \\
\hline CT & 61 (39.10 \%) & 56 (35.90\%) & & \\
\hline TT & $17(10.90 \%)$ & 27 (17.31 \%) & & \\
\hline Allele & & & \multirow[b]{2}{*}{1.142} & \multirow[b]{2}{*}{0.2852} \\
\hline $\begin{array}{l}\mathrm{C} \\
\mathrm{T}\end{array}$ & $\begin{array}{l}106(67.95 \%) \\
50(32.05 \%)\end{array}$ & $\begin{array}{l}97(62.18 \%) \\
59(37.82 \%)\end{array}$ & & \\
\hline
\end{tabular}

TABLE 4: THE RESULTS OF CONFORMITY rs10877012 TO HARDY WEINBERG EQUILIBRIUM

\begin{tabular}{lllllll}
\hline rs10877012 & TT & GT & GG & Sum & $\chi^{2}$ & P \\
\hline Control group & 56 & 55 & 45 & 156 & 0.006 & 0.921 \\
SLE group & 72 & 67 & 17 & 156 & 0.844 & 0.357 \\
\hline
\end{tabular}

TABLE 5: THE RESULTS OF CONFORMITY rS4646536 TO HARDY WEINBERG EQUILIBRIUM

\begin{tabular}{|c|c|c|c|c|c|c|}
\hline rs4646536 & & $\mathrm{CC}$ & TT & Sum & $x^{2}$ & p \\
\hline Control group & 73 & 56 & 27 & 156 & 1.426 & 0.513 \\
\hline SLE group & 78 & 61 & 17 & 156 & 1.416 & 0.359 \\
\hline
\end{tabular}

TABLE 6: CORRELATION BETWEEN rs10877012 GENOTYPE AND CLINICOPATHOLOGICAL FEATURES

\begin{tabular}{|c|c|c|c|c|c|c|}
\hline & & $\begin{array}{c}\text { TT }(n=72) \\
n(\%)\end{array}$ & $\begin{array}{c}\text { GT }(n=67) \\
n(\%)\end{array}$ & $\begin{array}{c}\text { GG (n=17) } \\
n(\%)\end{array}$ & OR (95 \% Cl) & $\mathrm{p}$ \\
\hline \multirow[t]{2}{*}{ Renal damage } & Presence & $42(58.33 \%)$ & $36(53.73 \%)$ & $9(52.94 \%)$ & 1 & \\
\hline & Absence & 30 (41.67 \%) & 31 (46.27\%) & 8 (47.06 \%) & $1.05(0.62-1.76)$ & 0.78 \\
\hline \multirow{2}{*}{ Photosensitivity } & Presence & $53(73.61 \%)$ & $54(80.60 \%)$ & $10(58.82 \%)$ & 1 & \\
\hline & Absence & 19 (26.39\%) & 13 (19.40\%) & 7 (41.18 \%) & $0.67(0.43-1.04)$ & 0.53 \\
\hline \multirow[t]{2}{*}{ Vasculitis } & Presence & $50(69.44 \%)$ & 49 (73.13\%) & 12 (70.59) & 1 & \\
\hline & Absence & $22(30.56 \%)$ & $18(26.87 \%)$ & $5(29.41)$ & $1.07(0.86-1.32)$ & 0.75 \\
\hline Arthritis & $\begin{array}{c}\text { Presence } \\
\text { Absence }\end{array}$ & $\begin{array}{c}7(9.72 \%) \\
65(90.28 \%)\end{array}$ & $\begin{array}{l}20(29.86 \%) \\
47(70.15 \%)\end{array}$ & $\begin{array}{c}6(35.29 \%) \\
11(64.71 \%)\end{array}$ & $\begin{array}{c}1 \\
3.85(2-10-10 \\
52)\end{array}$ & 01 \\
\hline
\end{tabular}

The correlation between different genotypes of rs10877012 locus and laboratory indicators (ANA, anti dsDNA and increased CRP) of SLE patients was analyzed by logistic regression. The results showed that the genotype distribution of rs10877012 locus was correlated with the occurrence of anti dsDNA and increased CRP $(\mathrm{p}<0.05)$. The proportion of positive ANA was higher in TT genotype carriers and the possibility of increased CRP was higher in TT genotype and GG genotype carriers. There was no significant difference between genotype distribution of rs10877012 and ANA $(p>0.05)$. See Table 7 for details.

SLE is an autoimmune disease due to over-function of T cells and B cells, which could harm to organs as skin, joints, central nervous system and kidney. The characteristics of SLE is the booming auto-antibodies, systemic regulatory $\mathrm{T}$ cell depletion, increase of $\mathrm{T}$ Helper 17 Cells (Th17) and excessive proliferation of $\mathrm{B}$ cells ${ }^{[8]}$. CYP27B1 is one of the main genes involved in the metabolic pathway of $1 \alpha, 25$ dihydroxyvitamin D. A variety of immune cells including monocyte macrophages, dendritic cells, B lymphocytes and T lymphocytes express CYP27B1 and can convert $25(\mathrm{OH})$ D3 into active $1 \alpha, 25$ dihydroxyvitamin
$\mathrm{D}^{[9]}$. In order to discover the relationship between CYP27B1 genotype and SLE, we measured $-1260 \mathrm{G} / \mathrm{T}$ (rs10877012) and $+2838 \mathrm{~T} / \mathrm{C}$ (rs4646536) genotypes of CYP27B1 in 156 SLE patients and 156 healthy controls samples by PCR-ligase detection reaction. Genotyping to identify the allele differences of SNP and correlation analysis according to the linkage disequilibrium relationship between loci are effective methods to demonstrate disease-related genetic loci and finally locate the pathogenic genes in the large population. The results showed that the gene distributions of rs 10877012 and rs4646536 in SLE group and control group were consistent with Hardy Weinberg equilibrium, indicated that both groups came from the same Mendelian population. The genotype and allele frequencies of rs10877012 in SLE patients were different from those in healthy control group. The genotype TT and GT were higher than those in control group and the genotype GG was lower than those in control group. There was no significant difference in rs4646536 genotype and allele frequency between SLE patients and healthy controls.

In this study, unconditional logistic regression model was also used to calculate the OR and $95 \%$ CI between genotype rs10877012 and clinical characteristics of 
www.ijpsonline.com

TABLE 7: CORRELATION BETWEEN rs10877012 GENOTYPE AND LABORATORY INDICATORS

\begin{tabular}{|c|c|c|c|c|c|c|}
\hline \multirow{2}{*}{$\begin{array}{l}\text { Laboratory } \\
\text { indicators }\end{array}$} & \multirow{2}{*}{$\begin{array}{l}\text { Positive/ } \\
\text { Negative }\end{array}$} & TT $(n=72)$ & GT $(n=67)$ & GG (n=17) & \multirow{2}{*}{$x^{2}$} & \multirow{2}{*}{$\mathrm{p}$} \\
\hline & & n (\%) & n (\%) & n (\%) & & \\
\hline \multirow{2}{*}{ ANA } & $(+)$ & $69(95.83 \%)$ & $65(97.01 \%)$ & $17(100 \%)$ & 1.00 & \\
\hline & $(-)$ & $3(4.17 \%)$ & $2(2.99 \%)$ & $0(0 \%)$ & $1.15(0.54-3.14)$ & 0.75 \\
\hline \multirow{2}{*}{ Anti-dsDNA } & $(+)$ & 56 (77.78 \%) & $30(44.78 \%)$ & 7 (41.18 \%) & 1.00 & \\
\hline & $(-)$ & $16(22.22 \%)$ & 37 (55.22 \%) & $10(58.82 \%)$ & $2.73(1.09-9.44)$ & 0.03 \\
\hline \multirow{2}{*}{ Increased CRP } & $(+)$ & 40 (55.56 \%) & $28(41.79 \%)$ & $13(76.47 \%)$ & 1.00 & \\
\hline & $(-)$ & 32 (44.44 \%) & 39 (58.21\%) & $4(23.53 \%)$ & $2.65(0.94-8.17)$ & 0.03 \\
\hline
\end{tabular}

patients with SLE. The results showed that rs10877012 polymorphism was associated with arthritis happened in patients with SLE, but not associated with renal damage, hypersensitivity and vasculitis; rs10877012 polymorphism was associated with anti dsDNA and increased CRP in laboratory indexes, but not associated with the positive of ANA.

At present, there are few studies on the pathogenesis of lupus erythematosus at the gene polymorphism level of CYP27B1. Through the above experiments, this study reveals the genetic mechanism of the role of CYP27B1 in the occurrence and development of systemic lupus erythematosus, providing new evidences and reference for the study of basic mechanism and genetic pathology of systemic lupus erythematosus, and provides new ideas for the clinical diagnosis and treatment of SLE.

\section{Acknowledgements:}

This work was supported by the Hainan Province Key R\&D Program Tasks (ZDYF2019166). Zan Liu and Mei Qiong Huang are contributed equally to this work. Qian Qi Lin and Wei Fei Chen are considered co-corresponding authors in our study.

\section{Conflict of interests:}

The authors declared no conflicts of interest.

\section{REFERENCES}

1. Carlsen AL, Schetter AJ, Nielsen CT, Lood C, Knudsen S, Voss A, et al. Circulating microRNA expression profiles associated with systemic lupus erythematosus. Arthritis Rheum 2013;65(5):1324-34.
2. Liu N, Su H, Zhang Y, Kong J. The protective effect of $1,25(\mathrm{OH})_{2} \mathrm{D} 3$ against cardiac hypertrophy is mediated by the cyclin-dependent kinase inhibitor p21. Eur J Pharmacol 2020;888:173510.

3. de Carvalho JF. Negativization of antinuclear, anti-dsDNA and anti-chromatin antibodies after vitamin $\mathrm{D}$ supplementation in a lupus patient. Clin Nutr ESPEN 2021;42:262-4.

4. Liu Y, Li L, Yi B, Hu ZX, Li AM, Yang C, et al. Activation of vitamin D receptor attenuates high glucose-induced cellular injury partially dependent on CYP2J5 in murine renal tubule epithelial cell. Life Sci 2019;234:116755.

5. Latacz M, Snarska J, Kostyra E, Wroński K, Fiedorowicz E, Savelkoul H, et al. CYP27B1 gene polymorphism rs10877012 in patients diagnosed with colorectal cancer. Nutrients 2020;12(4):998.

6. Ma X, Xie Z, Qin J, Luo S, Zhou Z. Association of vitamin D pathway gene CYP27B1 and CYP2R1 polymorphisms with autoimmune endocrine disorders: A meta-analysis. J Clin Endocrinol Metab 2020;105(11):3575-87.

7. Revised 2003 consultation on diagnostic criteria and longterm health risks related to Polycrystalline Ovary Syndrome (PCOS). Hum Reprod 2004;19(1):41-7.

8. Terrier B, Derian N, Schoindre Y, Chaara W, Geri G, Zahr N, et al. Restoration of regulatory and effector $\mathrm{T}$ cell balance and B cell homeostasis in systemic lupus erythematosus patients through vitamin D supplementation. Arthritis Res Ther 2012;14(5):1-0.

9. Li N, Wu HM, Hang F, Zhang YS, Li MJ. Women with recurrent spontaneous abortion have decreased $25(\mathrm{OH})$ vitamin D and VDR at the fetal-maternal interface. Braz J Med Biol Res 2017;50(11):e6527.

This is an open access article distributed under the terms of the Creative Commons Attribution-NonCommercial-ShareAlike 3.0 License, which allows others to remix, tweak, and build upon the work non-commercially, as long as the author is credited and the new creations are licensed under the identical terms

This article was originally published in a special issue, "Novel Therapeutic Approaches in Biomedicine and Pharmaceutical Sciences" Indian J Pharm Sci 2021:83(6) Spl Issue "105-109" 